\title{
Efficacy of Systemic Oncological Treatments in Patients With Advanced Esophageal or Gastric Cancers at High Risk of Dying in the Middle and Short Term: An Overview of Systematic Reviews
}

\author{
Marilina Santero \\ Iberoamerican Cochrane Centre, Biomedical Research Institute Sant Pau (IIB Sant Pau), Barcelona \\ Javier Pérez-Bracchiglione \\ Interdisciplinary Centre for Health Studies (CIESAL), Universidad de Valparaíso, Viña del Mar \\ Roberto Acosta-Dighero \\ Department of Physical Therapy, Faculty of Medicine, Universidad de Chile, Santiago \\ Adriana Gabriela Meade \\ Iberoamerican Cochrane Centre, Biomedical Research Institute Sant Pau (IIB Sant Pau), Barcelona \\ Alba Antequera Martín \\ Iberoamerican Cochrane Centre, Biomedical Research Institute Sant Pau (IIB Sant Pau), Barcelona \\ Ariadna Auladell-Rispau \\ Iberoamerican Cochrane Centre, Biomedical Research Institute Sant Pau (IIB Sant Pau), Barcelona \\ Maria Jesús Quintana \\ Iberoamerican Cochrane Centre, Biomedical Research Institute Sant Pau (IIB Sant Pau), Barcelona \\ Carolina Requeijo \\ Iberoamerican Cochrane Centre, Biomedical Research Institute Sant Pau (IIB Sant Pau), Barcelona \\ Gerardo Rodríguez-Grijalva \\ Iberoamerican Cochrane Centre, Biomedical Research Institute Sant Pau (IIB Sant Pau), Barcelona \\ Rosario Dorantes-Romadía \\ Iberoamerican Cochrane Centre, Biomedical Research Institute Sant Pau (IIB Sant Pau), Barcelona \\ Josefina Salazar \\ Iberoamerican Cochrane Centre, Biomedical Research Institute Sant Pau (IIB Sant Pau), Barcelona \\ Ivan Solà \\ Iberoamerican Cochrane Centre, Biomedical Research Institute Sant Pau (IIB Sant Pau), Barcelona \\ Urrútia Gerard \\ Iberoamerican Cochrane Centre, Biomedical Research Institute Sant Pau (IIB Sant Pau), Barcelona \\ Xavier Bonfill-Cosp ( $\square$ xbonfill@santpau.cat) \\ Iberoamerican Cochrane Centre, Biomedical Research Institute Sant Pau (IIB Sant Pau), Barcelona \\ Karla Salas-Gama \\ Iberoamerican Cochrane Centre, Biomedical Research Institute Sant Pau (IIB Sant Pau), Barcelona
}

\section{Research Article}

Keywords: Esophageal Cancer, Gastric Cancer, Antineoplastic Agents, Biological Therapy, Molecular Targeted Therapy, Immunotherapy, Review Literature as Topic, Systematic reviews.

Posted Date: February 4th, 2021

DOl: https://doi.org/10.21203/rs.3.rs-151401/v1

License: (c) (1) This work is licensed under a Creative Commons Attribution 4.0 International License. Read Full License 


\section{Abstract \\ Background}

Esophageal and gastric cancers are a significant public health problem worldwide, with most patients presenting with advanced-stage disease and, consequently, poor prognosis. Systemic oncological treatments (SOT) have been widely used over more conservative approaches, such as supportive care. Nevertheless, its effectiveness in this scenario is not sufficiently clear. This paper provides an overview of systematic reviews that assessed the effectiveness of SOT compared with the best supportive care (BSC) or placebo in patients with advanced esophageal or gastric cancers in an end-of-life context.

\section{Methods}

We searched MEDLINE, EMBASE, The Cochrane Library, Epistemonikos, and PROSPERO for eligible systematic reviews (SRs) published from 2008 onwards. The primary outcomes were overall survival (OS), progression-free survival (PFS), functional status, and toxicity. Two authors assessed eligibility and extracted data independently. We evaluated the methodological quality of included SRs using the AMSTAR-2 tool and the overlap of primary studies (corrected covered area, CCA). Also, we performed a de novo meta-analysis with data reported for each primary study when it was possible. We assessed the certainty of evidence using the GRADE approach.

\section{Results}

We identified 16 SRs (19 included trials) for inclusion within this overview. Most reviews had a critically low methodological quality, and there was a very high overlap of primary studies. It is uncertain whether SOT improves OS and PFS over more conservative approaches due to the very low certainty of evidence.

\section{Conclusions}

The evidence is very uncertain about the effectiveness of SOT for advanced esophageal or gastric cancers. High-quality SRs and further randomized clinical trials that include a thorough assessment of patient-centered outcomes are needed.

\section{Registration:}

Open Science Framework, DOI 10.17605/OSF.IO/7CHX6.

\section{Background}

Worldwide, esophageal and gastric cancers are a significant public health problem, with approximately 509,000 and 783,000 deaths in 2018, respectively.(1) Their combined mortality for both tumor sites is over 1.2 million, leading to the second most common cancer death cause after lung cancer. While global reports have shown a decrease in gastric cancer mortality rates over the past 20 years, a steady increase in esophageal cancer rates has been observed mainly in the Western Pacific and European regions.(2) Moreover, both cancers are overly aggressive; despite their relatively low incidence, they often have a poor prognosis since the diagnosis is usually late. $(3,4)$ In a metastatic stage, esophageal and gastric cancers have less than $30 \%$ survival at one year and less than $5 \%$ at five years, respectively.(5) Due to the above, many patients are in a terminal care period with progressive disease and months or less of expected survival which has been conceptualized by some authors as "end of life" (EOL). $(6,7)$

The use of systemic oncological treatments (SOT) has been widely investigated for esophageal and gastric cancers, and as a consequence, chemotherapy (CT), targeted therapy, and immunotherapy are largely used to try improving survival and quality of life $(\mathrm{QoL})$. $(8,9)$ However, its use in the EOL context is still subject to controversy. Some authors have reported patients experiencing emotional distress, severely reduced QoL, a range of diagnosis-specific and treatment-related problems, and side effects related to these treatments.(10,11) The overuse of SOT close to death could be an indicator of low-quality medical care, defined as the underuse of known effective practices, or equivocal effectiveness according to the provider rather than patient preferences.(12)

More knowledge is needed to improve the ability of the current healthcare system to deliver timely and appropriate EOL care. Among patients with esophageal or gastric cancers with poor prognosis, a palliative care approach is imperative.(13) In this sense, best supportive care (BSC) may include a range of multidisciplinary interventions, such as symptomatic control by radiotherapy, palliative surgery, and management of antineoplastic-treatment-related toxicities, analgesia, and psychological or social assistance. (13-15)

It would be very useful to know the precise balance of whether these effective treatments compensate for the adverse effects and costs they have for patients and society. Therefore, it is of central importance to evaluate the appropriateness of the SOT compared to the existing alternatives, such as BSC, in terms of effectiveness with special consideration for the patient's QoL near death and relief of the significant physical and psychological symptomatic burden that these patients present. Thus, this study aims to make a comprehensive synthesis of the available evidence regarding the effectiveness of SOT from systematic reviews (SRs) compared with BSC or placebo in patients with advanced esophageal or gastric cancers in an EOL context.

\section{Methods}


We performed an overview of SRs on patients with advanced esophageal or gastric cancers published from 2088 onwards. The current study is part of a broader evidence syntheses project that aims to assess the effectiveness of SOT versus BSC for patients with advanced non-intestinal digestive cancer (esophageal, gastric, hepatobiliary, and pancreatic cancer). We registered the protocol detailing the methods in the Open Science Framework [see protocol in Appendix 1](16) and we conducted this overview according to rigorous standards aligned to Cochrane Methodology(17) and reported our results according to PRISMA (Preferred Reporting Items for Systematic Reviews and Meta-Analyses) guidelines(18) [see the completed checklist in Appendix 2].

\section{Search strategy and selection criteria}

Figure 1 ("Figure 1. Eligibility criteria") presents our eligibility criteria. We included SRs that assessed SOT's impact in esophageal or gastric cancer patients at high risk of dying in the short or medium term. We searched for the following outcomes: 1) overall survival (OS); 2) progression-free survival (PFS); 3 ) functional status (FS); 4) toxicity; 5) symptoms related to the disease; 6) quality of life (QoL); 7) admissions to hospital or long-term center, or emergency consultations; 8 ) quality of death (admission to the hospital at the end-of-life; palliative care provided during the last year; place of death). We considered the following as primary outcomes: OS, QoL, FS, and toxicity.

We searched in four bibliographic databases: MEDLINE (access via PubMed), the Cochrane Database of Systematic Reviews, Epistemonikos from inception to September 30th, 2019, and EMBASE (access via Ovid) from inception to October 7th, 2019. We did not restrict our search by language. We provide a detailed search strategy elsewhere.(16) The search strategy for PubMed is described in Appendix 3. Two previously trained reviewers performed an independent title and abstract screening and a full-text screening afterward. A third reviewer solved any disagreements. We used Covidence for all the screening process.(19)

\section{Data extraction and Risk of Bias Assessment}

One reviewer extracted data from the included studies using a previously piloted data extraction sheet, and a second author cross-checked this process. We extracted from the included SRs both synthesized findings and disaggregated data on reported outcomes of interest for each primary study. One author assessed the methodological quality for each included SR using the AMSTAR-2 tool, and a second author cross-checked this assessment.(20) We reported the risk of bias assessment of primary studies undertaken by the authors of each SR. When two or more SRs had a conflicting risk of bias assessments for a primary study, we reported the one assessed by the Cochrane tool. If disagreement persisted, we reported the assessment of the SR with better methodological quality according to AMSTAR-2 (if the reviews had the same quality, we selected the most frequent judgment from the primary study assessment). Lastly, if a discrepancy remained, we reported it as "no agreement".

\section{Assessment of overlap of primary studies}

We built a matrix of evidence to assess the overlap of primary studies within SRs. We computed the matrix cross-linking the relevant randomized control trials (RCTs) in eligible SRs for this overview and calculated the corrected covered area (CCA). We considered a CCA below $5 \%$ as slight overlap, a CCA $\geq 5 \%$ and < $10 \%$ as moderate overlap, a CCA $\geq 10 \%$ and $<15 \%$ as high overlap, and a CCA $\geq 15 \%$ as a very high overlap.(21)

\section{Data synthesis and analysis}

We presented a narrative synthesis of the included reviews and summarised the main results on the effectiveness of SOT regarding relevant outcomes. We performed a de novo meta-analysis based on primary studies data included in eligible SRs when possible for each comparison. We analyzed dichotomous outcomes with odds ratio (OR), continuous outcomes with the mean difference or standardized mean difference, and time-to-event outcomes with hazard ratios (HR), all of these with a $95 \%$ confidence interval $(95 \% \mathrm{Cl})$. We assessed the heterogeneity of the included studies with $\mathrm{I}^{2}$ as follows: $\mathrm{I}^{2}<50 \%$ as low heterogeneity, $I^{2}>50 \%$ and $<90 \%$ as high, and $>90 \%$ as very high. When heterogeneity was below $90 \%$, we performed a meta-analysis in RevMan 5.4 using a random-effects model. We reported all the outcomes according to a type of SOT (chemotherapy, immunotherapy, and targeted/biological therapies). We also conducted a sensitivity analysis, considering only studies in which comparison is described explicitly as BSC.

\section{Assessment of certainty of the evidence}

We assessed the certainty of the evidence for each primary outcome according to the Grading of Recommendations Assessment, Development, and Evaluation (GRADE) guidance and performed a Summary of Findings (SoF) table.(22) We classified the certainty of the evidence for each outcome as high, moderate, low, or very low. We also reported the SoF in plain-language summary.

\section{Results}

Our initial searches yielded 2452 results, and 191 were evaluated as full-text articles following title and abstract screening. According to the eligibility criteria, we included 16 SRs in this overview.(15, 23-37) Fig. 2(“Figure 2. PRISMA flow diagram") presents the PRISMA flow diagram. Reasons for exclusion and references to 175 final excluded articles are given in Appendix 4.

Table 1 and Appendix 5 summarise the general characteristics of included SRs. Of the included reviews, two were Cochrane SRs (15, 29), and four were network meta-analyses. $(28,31,32,34)$ Included SRs were published between 2014 and 2020, nine were performed in high-income countries, and seven of them in China. All SRs included meta-analyses except for Harvey 2017. (28) Three SRs exclusively addressed patients with gastric cancer (23, 25, 30), nine reviews included only patients with gastric cancer including the gastroesophageal junction (GEJ) $(26-29,31-33,35,37)$ and the remaining four considered both patients with esophageal and GEJ cancer. $(15,24,34,36)$ The retrieved SRs included a total of 19 primary studies relevant to our question (See Appendix 6). 
Table 1

General characteristics of included systematic reviews

\begin{tabular}{|c|c|c|c|c|c|c|c|c|c|c|}
\hline $\begin{array}{l}\text { Author, } \\
\text { year }\end{array}$ & Country & $\begin{array}{l}\text { Time } \\
\text { frame }\end{array}$ & $\begin{array}{l}\text { Search strategy/ } \\
\text { Database }\end{array}$ & $\begin{array}{l}\text { RCTs } \\
\text { (n) }\end{array}$ & $\begin{array}{l}\text { RCTs (n) } \\
\text { included } \\
\text { in our } \\
\text { overview. }\end{array}$ & $\mathbf{P}$ & I & $\mathrm{C}$ & 0 & Funding \\
\hline $\begin{array}{l}\text { lacovelli } \\
2014 \\
{[38]}\end{array}$ & USA & $\begin{array}{l}\text { From } \\
\text { January } \\
2004 \text { to } \\
\text { February } \\
2014\end{array}$ & $\begin{array}{l}\text { Cochrane } \\
\text { Central Register } \\
\text { of Controlled } \\
\text { Trials, MEDLINE, } \\
\text { PubMed. }\end{array}$ & 5 & 5 & $\begin{array}{l}\text { Gastric } \\
\text { cancer }\end{array}$ & $\begin{array}{l}\text { CT, Biological, } \\
\text { or targeted } \\
\text { therapy }\end{array}$ & $\begin{array}{l}\text { BSC / } \\
\text { Supportive } \\
\text { care }\end{array}$ & $\begin{array}{l}\text { Functional } \\
\text { status, OS }\end{array}$ & No \\
\hline $\begin{array}{l}\text { TerVeer } \\
2016 \\
{[24]}\end{array}$ & Netherlands & $\begin{array}{l}\text { Up to } \\
\text { January } \\
2016\end{array}$ & $\begin{array}{l}\text { Cochrane } \\
\text { Central Register } \\
\text { of Controlled } \\
\text { Trials, EMBASE, } \\
\text { MEDLINE. }\end{array}$ & 28 & 8 & $\begin{array}{l}\text { Esophageal, } \\
\text { gastric, and } \\
\text { GEJ cancer }\end{array}$ & $\begin{array}{l}\text { CT, Biological, } \\
\text { or targeted } \\
\text { therapy }\end{array}$ & $\begin{array}{l}\text { BSC / } \\
\text { Placebo }\end{array}$ & $\begin{array}{l}\text { OS, PFS, } \\
\text { Toxicity }\end{array}$ & No \\
\hline $\begin{array}{l}\text { Wang } \\
2016 \\
{[25]}\end{array}$ & China & $\begin{array}{l}\text { Up to } \\
\text { December } \\
31,2015\end{array}$ & $\begin{array}{l}\text { Cochrane } \\
\text { Library, } \\
\text { EMBASE, } \\
\text { PubMed }\end{array}$ & 10 & 3 & $\begin{array}{l}\text { Gastric } \\
\text { cancer }\end{array}$ & $\begin{array}{l}\text { Biological or } \\
\text { targeted } \\
\text { therapy }\end{array}$ & Placebo & os & Public \\
\hline $\begin{array}{l}\text { Chan a } \\
2017 \\
{[26]}\end{array}$ & Australia & $\begin{array}{l}\text { Up to } \\
\text { December } \\
2014\end{array}$ & $\begin{array}{l}\text { Cochrane } \\
\text { Central Register } \\
\text { of Controlled } \\
\text { Trials, EMBASE, } \\
\text { PubMed. }\end{array}$ & 15 & 4 & $\begin{array}{l}\text { Gastric and } \\
\text { GEJ cancer }\end{array}$ & $\begin{array}{l}\text { Biological or } \\
\text { targeted } \\
\text { therapy }\end{array}$ & Placebo & $\begin{array}{l}\text { OS, PFS, } \\
\text { Toxicity, } \\
\text { QoL }\end{array}$ & No \\
\hline $\begin{array}{l}\text { Chan b } \\
2017 \\
{[27]}\end{array}$ & China & $\begin{array}{l}\text { Up to } \\
2016\end{array}$ & $\begin{array}{l}\text { CINAHL, } \\
\text { Cochrane } \\
\text { Central Register } \\
\text { of Controlled } \\
\text { Trials, EMBASE, } \\
\text { MEDLINE }\end{array}$ & 5 & 5 & $\begin{array}{l}\text { Gastric and } \\
\text { GEJ cancer }\end{array}$ & $\begin{array}{l}\text { CT, Biological, } \\
\text { or targeted } \\
\text { therapy }\end{array}$ & $\begin{array}{l}\text { BSC / } \\
\text { Placebo }\end{array}$ & $\begin{array}{l}\text { OS, PFS, } \\
\text { Toxicity }\end{array}$ & No \\
\hline $\begin{array}{l}\text { Harvey } \\
2017 \\
{[28]}\end{array}$ & UK & $\begin{array}{l}\text { Between } \\
1990 \text { and } \\
2015\end{array}$ & $\begin{array}{l}\text { PubMed, } \\
\text { Scopus. }\end{array}$ & 5 & 5 & $\begin{array}{l}\text { Gastric and } \\
\text { GEJ cancer }\end{array}$ & CT & BSC & OS & NR \\
\hline $\begin{array}{l}\text { Janmaat } \\
2017 \\
{[54]}\end{array}$ & Netherlands & $\begin{array}{l}\text { Up to } 13 \\
\text { May } 2015\end{array}$ & $\begin{array}{l}\text { Cochrane } \\
\text { Central Register } \\
\text { of Controlled } \\
\text { Trials, } \\
\text { Clinicaltrials.gov, } \\
\text { EMBASE, Google } \\
\text { Scholar, } \\
\text { MEDLINE, } \\
\text { PubMed, Web of } \\
\text { Science, WHO } \\
\text { International } \\
\text { Clinical Trials } \\
\text { Registry } \\
\text { Platform } \\
\text { (ICTRP) }\end{array}$ & 41 & 5 & $\begin{array}{l}\text { Esophageal } \\
\text { and GEJ } \\
\text { cancer }\end{array}$ & $\begin{array}{l}\text { CT, Biological, } \\
\text { or targeted } \\
\text { therapy }\end{array}$ & $\begin{array}{l}\text { BSC / } \\
\text { Placebo / } \\
\text { Non- } \\
\text { specified }\end{array}$ & OS & Public \\
\hline $\begin{array}{l}\text { Wagner } \\
2017 \\
{[29]}\end{array}$ & Switzerland & $\begin{array}{l}\text { Up to June } \\
2016\end{array}$ & $\begin{array}{l}\text { Cochrane } \\
\text { Central Register } \\
\text { of Controlled } \\
\text { Trials, MEDLINE, } \\
\text { Hand searched } \\
\text { reference lists } \\
\text { from studies, } \\
\text { abstracts, } \\
\text { conference. }\end{array}$ & 64 & 3 & $\begin{array}{l}\text { Gastric and } \\
\text { GEJ cancer }\end{array}$ & CT & BSC & os & Public \\
\hline $\begin{array}{l}\text { Wang } \\
2017 \\
{[30]}\end{array}$ & China & $\begin{array}{l}\text { Up to } \\
\text { December } \\
2015\end{array}$ & $\begin{array}{l}\text { Embase, } \\
\text { Medline, the } \\
\text { Cochrane } \\
\text { Central Register } \\
\text { of Controlled } \\
\text { Trials, Cochrane } \\
\text { Database of } \\
\text { Systematic } \\
\text { Reviews, } \\
\text { EMBASE, } \\
\text { MEDLINE }\end{array}$ & 9 & $\begin{array}{l}\text { Gastric } \\
\text { cancer }\end{array}$ & $\begin{array}{l}\text { Biological } \\
\text { or targeted } \\
\text { therapy }\end{array}$ & Placebo & Toxicity & NR & None \\
\hline $\begin{array}{l}\text { Xie } 2017 \\
{[31]}\end{array}$ & China & $\begin{array}{l}\text { Between } \\
\text { January } \\
1 \text { st, } 2000 \\
\text { and } \\
\text { October } \\
\text { 1st, } 2016\end{array}$ & $\begin{array}{l}\text { Cochrane } \\
\text { Library and } \\
\text { Scopus, } \\
\text { EMBASE, }\end{array}$ & 23 & 2 & $\begin{array}{l}\text { Gastric and } \\
\text { GEJ cancer }\end{array}$ & $\begin{array}{l}\text { CT, Biological, } \\
\text { or targeted } \\
\text { therapy }\end{array}$ & Placebo & os & NR \\
\hline
\end{tabular}

GEJ: gastroesophageal junction, P: patients, I: intervention, C: comparator, O: outcomes, CT: chemotherapy, BSC: best supportive care, OS: overall survival, PF QoL: quality of life, NR: not reported 


\begin{tabular}{|c|c|c|c|c|c|c|c|c|c|c|}
\hline $\begin{array}{l}\text { Author, } \\
\text { year }\end{array}$ & Country & $\begin{array}{l}\text { Time } \\
\text { frame }\end{array}$ & $\begin{array}{l}\text { Search strategy/ } \\
\text { Database }\end{array}$ & $\begin{array}{l}\text { RCTs } \\
\text { (n) }\end{array}$ & $\begin{array}{l}\text { RCTs (n) } \\
\text { included } \\
\text { in our } \\
\text { overview. }\end{array}$ & $P$ & I & C & 0 & Funding \\
\hline $\begin{array}{l}\text { Zhu } \\
2017 \\
{[32]}\end{array}$ & Canada & $\begin{array}{l}\text { Up to June } \\
2014\end{array}$ & $\begin{array}{l}\text { American } \\
\text { Society of } \\
\text { Clinical } \\
\text { Oncology } \\
\text { abstracts, } \\
\text { Cochrane } \\
\text { Central Register } \\
\text { of Controlled } \\
\text { Trials, EMBASE, } \\
\text { MEDLINE. }\end{array}$ & 8 & 5 & $\begin{array}{l}\text { Gastric and } \\
\text { GEJ cancer }\end{array}$ & $\begin{array}{l}\text { CT, Biological, } \\
\text { or targeted } \\
\text { therapy }\end{array}$ & $\begin{array}{l}\text { BSC / } \\
\text { Placebo }\end{array}$ & OS & Private \\
\hline $\begin{array}{l}\text { Liu } 2018 \\
\text { [33] }\end{array}$ & China & $\begin{array}{l}\text { Up to } \\
\text { March 15, } \\
2017\end{array}$ & $\begin{array}{l}\text { Cochrane } \\
\text { Central Register } \\
\text { of Controlled } \\
\text { Trials, } \\
\text { Clinicaltrials.gov, } \\
\text { EMBASE, EU } \\
\text { Clinical Trials } \\
\text { Register, Japan } \\
\text { Pharmaceutical } \\
\text { Information } \\
\text { Center, PubMed. }\end{array}$ & 8 & 4 & $\begin{array}{l}\text { Gastric and } \\
\text { GEJ cancer }\end{array}$ & $\begin{array}{l}\text { Biological or } \\
\text { targeted } \\
\text { therapy }\end{array}$ & Placebo & $\begin{array}{l}\text { OS, PFS, } \\
\text { Toxicity }\end{array}$ & $\begin{array}{l}\text { Public / } \\
\text { Private }\end{array}$ \\
\hline $\begin{array}{l}\text { Zhao } \\
2018 \\
{[34]}\end{array}$ & China & $\begin{array}{l}\text { Between } \\
2002 \text { and } \\
2017\end{array}$ & $\begin{array}{l}\text { Cochrane } \\
\text { Library, } \\
\text { EMBASE, } \\
\text { PubMed. }\end{array}$ & 16 & 6 & $\begin{array}{l}\text { Esophageal, } \\
\text { gastric and } \\
\text { GEJ }\end{array}$ & $\begin{array}{l}\text { Biological or } \\
\text { targeted } \\
\text { therapy }\end{array}$ & Placebo & $\begin{array}{l}\text { OS, PFS, } \\
\text { Toxicity }\end{array}$ & Public \\
\hline $\begin{array}{l}\text { Chen } \\
2019 \\
{[35]}\end{array}$ & China & $\begin{array}{l}\text { Up to } \\
\text { September } \\
2018\end{array}$ & PubMed & 9 & 2 & $\begin{array}{l}\text { Gastric and } \\
\text { GEJ cancer }\end{array}$ & Immunotherapy & $\begin{array}{l}\text { BSC / } \\
\text { Placebo }\end{array}$ & $\begin{array}{l}\text { OS, PFS, } \\
\text { Toxicity }\end{array}$ & Public \\
\hline $\begin{array}{l}\text { van } \\
\text { Kleef } \\
2019 \\
{[36]}\end{array}$ & Netherlands & $\begin{array}{l}\text { Up to April } \\
2018\end{array}$ & $\begin{array}{l}\text { Cochrane } \\
\text { Central Register } \\
\text { of Controlled } \\
\text { Trials, EMBASE, } \\
\text { MEDLINE. }\end{array}$ & 43 & 8 & $\begin{array}{l}\text { Esophageal, } \\
\text { gastric and } \\
\text { GEJ }\end{array}$ & $\begin{array}{l}\text { CT, Biological, } \\
\text { or targeted } \\
\text { therapy }\end{array}$ & $\begin{array}{l}\text { BSC / } \\
\text { Placebo }\end{array}$ & QoL & Public \\
\hline $\begin{array}{l}\text { Wallis } \\
2019 \\
{[37]}\end{array}$ & Canada & $\begin{array}{l}\text { Up to } \\
\text { October 2, } \\
2018\end{array}$ & $\begin{array}{l}\text { EMBASE, } \\
\text { MEDLINE, } \\
\text { PubMed, } \\
\text { Scopus. }\end{array}$ & 23 & 1 & $\begin{array}{l}\text { Gastric and } \\
\text { GEJ cancer }\end{array}$ & Immunotherapy & Placebo & OS & Private \\
\hline
\end{tabular}

GEJ: gastroesophageal junction, P: patients, I: intervention, C: comparator, O: outcomes, CT: chemotherapy, BSC: best supportive care, OS: overall survival, PF QoL: quality of life, NR: not reported

Figure 3 ("Figure 3. Overlap matrix") shows the overlap matrix of included reviews. The overall CCA was $17.19 \%$, which is considered as a very high overlap. Eight primary studies were included in two SRs $(24,36)$, and five in another five SRs. $(15,23,27,28,32)$

\section{Outcomes reported}

All reviews pre-specified outcome measures and reported OS, PFS, FS, toxicity, and QoL. None of the reviews examined symptoms related to the disease, admissions, or quality of death.

\section{Quality assessment of the included systematic reviews}

Using the AMSTAR-2 tool, we rated 13 out of 16 SRs (81\%) as critically low methodological quality (See Table 2). Only the review of Chan et. al 2017(27) was evaluated as high quality. Common critical flaws were the lack of report of an explicit protocol for conducting the SR, the lack of information on the sources of funding, and an inadequate assessment of the impact of the risk of bias of primary studies. 
Table 2

AMSTAR-2 SRS

\begin{tabular}{|c|c|c|c|c|c|c|c|c|c|c|}
\hline & $\begin{array}{l}\text { lacovelli } \\
2014\end{array}$ & $\begin{array}{l}\text { TerVeer } \\
2016\end{array}$ & Wang 2016 & $\begin{array}{l}\text { Chan } \\
2017 a\end{array}$ & $\begin{array}{l}\text { Chan } \\
\text { 2017b }\end{array}$ & $\begin{array}{l}\text { Harvey } \\
2017\end{array}$ & $\begin{array}{l}\text { Janmaat } \\
2017\end{array}$ & $\begin{array}{l}\text { Wagner } \\
2017\end{array}$ & Wang 2017 & $\begin{array}{l}\text { Xie } \\
2017\end{array}$ \\
\hline 1. & Yes & Yes & Yes & Yes & Yes & No & Yes & Yes & Yes & No \\
\hline 2. & No & No & No & No & Yes & No & Yes & Yes & Yes & No \\
\hline 3. & Yes & Yes & Yes & No & Yes & Yes & Yes & Yes & Yes & No \\
\hline 4. & Partial Yes & Yes & Yes & Yes & Yes & Partial Yes & Yes & Yes & Yes & Partial Ye؛ \\
\hline 5. & Yes & Yes & Yes & Yes & Yes & No & Yes & Yes & No & No \\
\hline 6. & Yes & Yes & Yes & Yes & Yes & Yes & Yes & Yes & Yes & Yes \\
\hline 7. & No & No & Yes & No & Yes & No & Yes & Yes & Yes & No \\
\hline 8. & Yes & Partial Yes & Yes & Partial Yes & Yes & Partial Yes & Yes & Yes & Yes & No \\
\hline 9a. & Partial Yes & Yes & Yes & Yes & Yes & Partial Yes & Yes & Yes & Partial Yes & No \\
\hline $9 \mathrm{~b}$. & $\begin{array}{l}\text { Includes } \\
\text { only RCTs }\end{array}$ & $\begin{array}{l}\text { Includes } \\
\text { only RCTs }\end{array}$ & $\begin{array}{l}\text { Includes } \\
\text { only RCTs }\end{array}$ & $\begin{array}{l}\text { Includes } \\
\text { only RCTs }\end{array}$ & $\begin{array}{l}\text { Includes } \\
\text { only RCTs }\end{array}$ & $\begin{array}{l}\text { Includes } \\
\text { only RCTs }\end{array}$ & $\begin{array}{l}\text { Includes } \\
\text { only RCTs }\end{array}$ & $\begin{array}{l}\text { Includes } \\
\text { only RCTs }\end{array}$ & $\begin{array}{l}\text { Includes } \\
\text { only RCTs }\end{array}$ & $\begin{array}{l}\text { Includes } \\
\text { only RCTs }\end{array}$ \\
\hline 10. & No & No & No & No & No & No & No & No & No & No \\
\hline 11a. & Yes & Yes & Yes & Yes & Yes & $\begin{array}{l}\text { No meta- } \\
\text { analysis } \\
\text { conducted }\end{array}$ & Yes & Yes & Yes & No \\
\hline $11 \mathrm{~b}$. & Yes & $\begin{array}{l}\text { No meta- } \\
\text { analysis } \\
\text { conducted }\end{array}$ & $\begin{array}{l}\text { No meta- } \\
\text { analysis } \\
\text { conducted }\end{array}$ & $\begin{array}{l}\text { No meta- } \\
\text { analysis } \\
\text { conducted }\end{array}$ & $\begin{array}{l}\text { No meta- } \\
\text { analysis } \\
\text { conducted }\end{array}$ & Yes & $\begin{array}{l}\text { No meta- } \\
\text { analysis } \\
\text { conducted }\end{array}$ & $\begin{array}{l}\text { No meta- } \\
\text { analysis } \\
\text { conducted }\end{array}$ & $\begin{array}{l}\text { No meta- } \\
\text { analysis } \\
\text { conducted }\end{array}$ & $\begin{array}{l}\text { No meta- } \\
\text { analysis } \\
\text { conductec }\end{array}$ \\
\hline 12. & No & No & Yes & Yes & Yes & No & Yes & Yes & Yes & Yes \\
\hline 13. & No & No & Yes & Yes & Yes & Yes & Yes & Yes & Yes & No \\
\hline 14. & No & Yes & Yes & Yes & Yes & Yes & Yes & Yes & Yes & No \\
\hline 15. & Yes & No & Yes & Yes & Yes & No & Yes & Yes & Yes & No \\
\hline 16. & No & Yes & Yes & Yes & Yes & No & Yes & Yes & No & Yes \\
\hline $\begin{array}{l}\text { QUALITY } \\
\text { OF THE } \\
\text { REVIEW }\end{array}$ & $\begin{array}{l}\text { CRITICALLY } \\
\text { LOW }\end{array}$ & $\begin{array}{l}\text { CRITICALLY } \\
\text { LOW }\end{array}$ & $\begin{array}{l}\text { CRITICALLY } \\
\text { LOW }\end{array}$ & $\begin{array}{l}\text { CRITICALLY } \\
\text { LOW }\end{array}$ & $\mathrm{HIGH}$ & $\begin{array}{l}\text { CRITICALLY } \\
\text { LOW }\end{array}$ & LOW & LOW & $\begin{array}{l}\text { CRITICALLY } \\
\text { LOW }\end{array}$ & $\begin{array}{l}\text { CRITICALI } \\
\text { LOW }\end{array}$ \\
\hline $\begin{array}{l}\text { Number } \\
\text { of } \\
\text { critical } \\
\text { flaws }\end{array}$ & 6 & 5 & 2 & 3 & 0 & 6 & 1 & 1 & 2 & 8 \\
\hline $\begin{array}{l}\text { Number } \\
\text { of non- } \\
\text { critical } \\
\text { flaws }\end{array}$ & 4 & 3 & 1 & 3 & 1 & 6 & 1 & 1 & 3 & 6 \\
\hline
\end{tabular}

1. Did the research questions and inclusion criteria for the review include the components of PICO? 2. Did the report of the review contain an explicit statemer report justify any significant deviations from the protocol? 3. Did the review authors explain their selection of the study designs for inclusion in the review? 4. authors perform study selection in duplicate? 6. Did the review authors perform data extraction in duplicate? 7. Did the review authors provide a list of exclud in adequate detail? 9a. RCT: Did the review authors use a satisfactory technique for assessing the risk of bias (RoB) in individual studies that were included i risk of bias (RoB) in individual studies that were included in the review? 10. Did the review authors report on the sources of funding for the studies included in methods for statistical combination of results? 11b. NSRI: If meta-analysis was performed did the review authors use appropriate methods for statistical con potential impact of RoB in individual studies on the results of the meta-analysis or other evidence synthesis? 13. Did the review authors account for RoB in in authors provide a satisfactory explanation for, and discussion of, any heterogeneity observed in the results of the review? 15. If they performed quantitative s study bias) and discuss its likely impact on the results of the review? 16. Did the review authors report any potential sources of conflict of interest, including a

\section{Risk of bias from the primary RCTs included in SRs}

Figure 4("Figure 4. Risk of bias Assessment") summarises the risk of bias of the included primary studies, as reported by the corresponding SR. Most reviews reported the risk of bias using The Cochrane Collaboration "Risk of Bias" tool, while four used the Jadad Scale. $(23,25,30,31)$ Three discrepancies between SR's assessments remained as "no agreement." (Bramhall 2002, Kang 2012, Kang 2017). A single domain (performance bias) of one primary trial (Glimelius 1997) was not reported.

\section{Effectiveness of systemic oncological treatment}

Due to the variability among the reviews and the outcomes reported, we could combine results only for OS and PFS (Figure 5 "Figure 5. Overall survival and progression-free survival for systemic oncological treatment versus supportive treatment in advanced esophageal or gastric cancers"). 


\section{Overall Survival}

CT for advanced gastric cancer: According to our de novo meta-analysis (Fig. 5.1), CT may improve OS over more conservative approaches (HR 0.44, 95\%Cl 0.33 to 0.58 ; five studies; low certainty). Wagner 2017 concludes that CT (first-line) improves survival (6.7 months) in comparison to BSC alone. Considering side effects and their impact on QoL, as well as the tumour burden and necessity to obtain a response rapidly, is the key in the treatment choice. As secondline treatment, lacovelli 2014 reported that CT were able to decrease the risk of death by $27 \%$. In patients with ECOG $=0$ a greater benefit was found for chemotherapy with a reduction of the risk of death by $43 \%$. This analysis reports that active and available therapies are able to prolong survival in patients with advanced gastric cancer with a different outcome based on initial patient's performance status.

CT for advanced esophageal cancer: According to our de novo meta-analysis (Fig. 5.2), it is very uncertain whether CT improves OS over more conservative approaches (HR 0.77, 95\% Cl 0.63 to 0.94; two studies; very low certainty). Based on Janmaat 2017 analysis, CT can be considered standard care for esophageal cancer. Nevertheless, main analysis included CT or targeted therapy agent(s) plus control intervention versus control intervention alone.

Immunotherapy for gastric cancer (including GEJ): According to our de novo meta-analysis (Fig. 5.3), it is very uncertain whether immunotherapy improves OS over more conservative approaches (HR $0.70,95 \% \mathrm{Cl} 0.52$ to 0.93 ; two studies; very low certainty). A network meta-analysis performed by Zhao 2018 concluded that apatinib, regorafenib, and rilotumumab improved patient OS.

Biological therapy for gastric cancer (including GEJ): According to our de novo meta-analysis (Fig. 5.4), biological therapy probably improves OS over more conservative approaches (HR 0.64, 95\% Cl 0.51 to 0.8; five studies; moderate certainty). Liu 2018 concluded that vascular endothelial growth factor receptor (VEGFR) drugs were effective targeted therapy in advanced or metastatic gastric cancer, and its toxicity is within a controllable range. VEGFR antibody drugs were more effective than VEGFR tyrosine kinase inhibitor drugs in terms of the OS of gastric cancer patients with little toxicity.

Targeted therapy for esophageal (including GEJ): According to Dutton et al. (2014), gefitinib (2nd-line) did not improve OS over more conservative approaches (HR 0.90, 95\% Cl 0.74 to 1.09). Dutton et al. 2014 investigated gefitinib in participants with progression after CT and excluded participants receiving cytotoxic $\mathrm{CT}$, immunotherapy, hormonal therapy, or radiotherapy to the site of measurable or evaluable disease within the four weeks prior to inclusion.

Biological therapy for gastric cancer: According to Ohtsu et al. (2013), everolimus $10 \mathrm{mg} / \mathrm{d}$ (2nd-line) did not improve OS over placebo (HR 0.90, Cl 0.74 to 1.09).

Targeted therapy for gastric cancer (including GEJ): According to Bramhalll 2002, marimastat improved survival $(\mathrm{HR}=1.23(\mathrm{Cl} 0.98$ to 1.55$), \mathrm{p}=0.07)$, and this modest difference was maintained over two years $(\mathrm{HR}=1.27$ ( $\mathrm{Cl} 1.03$ to 1.57$), \mathrm{p}=0.024)$. Median survival was 160 days for the intervention group and 138 days for the placebo the group. Two-year survival was $9 \%$ and $3 \%$, respectively. In a subgroup of 123 patients, who had received prior $\mathrm{CT}$, a significant survival benefit was identified ( $H R=1.53(\mathrm{Cl} 1.00$ to 2.34$), \mathrm{p}=0.045)$. This benefit was increased over two years $(\mathrm{HR}=1.68(1.16$ to 2.44$), p=0.006)$.

CT for esophageal and gastric cancers (including GEJ): According to Ford et al. (2014), docetaxel as second-line therapy improved OS over BSC (HR 0.67, Cl 0.49 to 0.92).

\section{Progression-free survival}

Biological therapy for gastric cancers (including GEJ): According to our de novo meta-analysis (Fig. 5.5), biological therapy (2nd and 3rd line) improved PFS over more conservative approaches (HR 0.34, 95\% Cl 0.25 to 0.45 ; I2 71\%; five studies). Liu 2018 concluded that VEGFR drugs were effective targeted therapy in advanced or metastatic gastric cancer, and its toxicity is within a controllable range. VEGFR antibody drugs were more effective than VEGFR tyrosine kinase inhibitor drugs in terms of the PFS of gastric cancer patients with little toxicity.

Biological and targeted therapy for gastric cancer: According to Bramhall et al. (2002), marimastat as second-line therapy did not improve PFS over placebo (HR 1.32, Cl 95\% 1.07 to 1.63).

Biological therapy for gastric cancer: According to Othsu et al. (2013), everolimus as the second and third line improved PFS over placebo or BSC (HR 0.66, CI 0.56 to 0.78$)$.

Immunotherapy for gastric cancer (including GEJ): According to Kang et al. (2017), nivolumab improved PFS over placebo (HR 0.60, Cl 0.49 to 0.75).

Biological therapy for esophageal cancer (including GEJ): According to Dutton et al. (2014), gefitinib (2nd line) improved PFS over placebo (HR 0.66, Cl 0.66 to 0.97).

Table 3 provides a narrative synthesis as an overview of the other outcomes. All the SRs that reported PFS showed a better PFS with SOTs than control (15, $24,26,27,33,34)$, while most of the SRs reporting adverse events showed more adverse events the intervention groups. $(24,26,27,29-31,33,35)$ There is scarce data related to QoL, and none of the included SRs reported findings for the outcomes FS, symptoms related to the disease, admissions, or quality of death. Appendix 7 provides SoF tables for the primary outcomes. 
Table 3

Narrative synthesis of clinical and patient centered outcomes

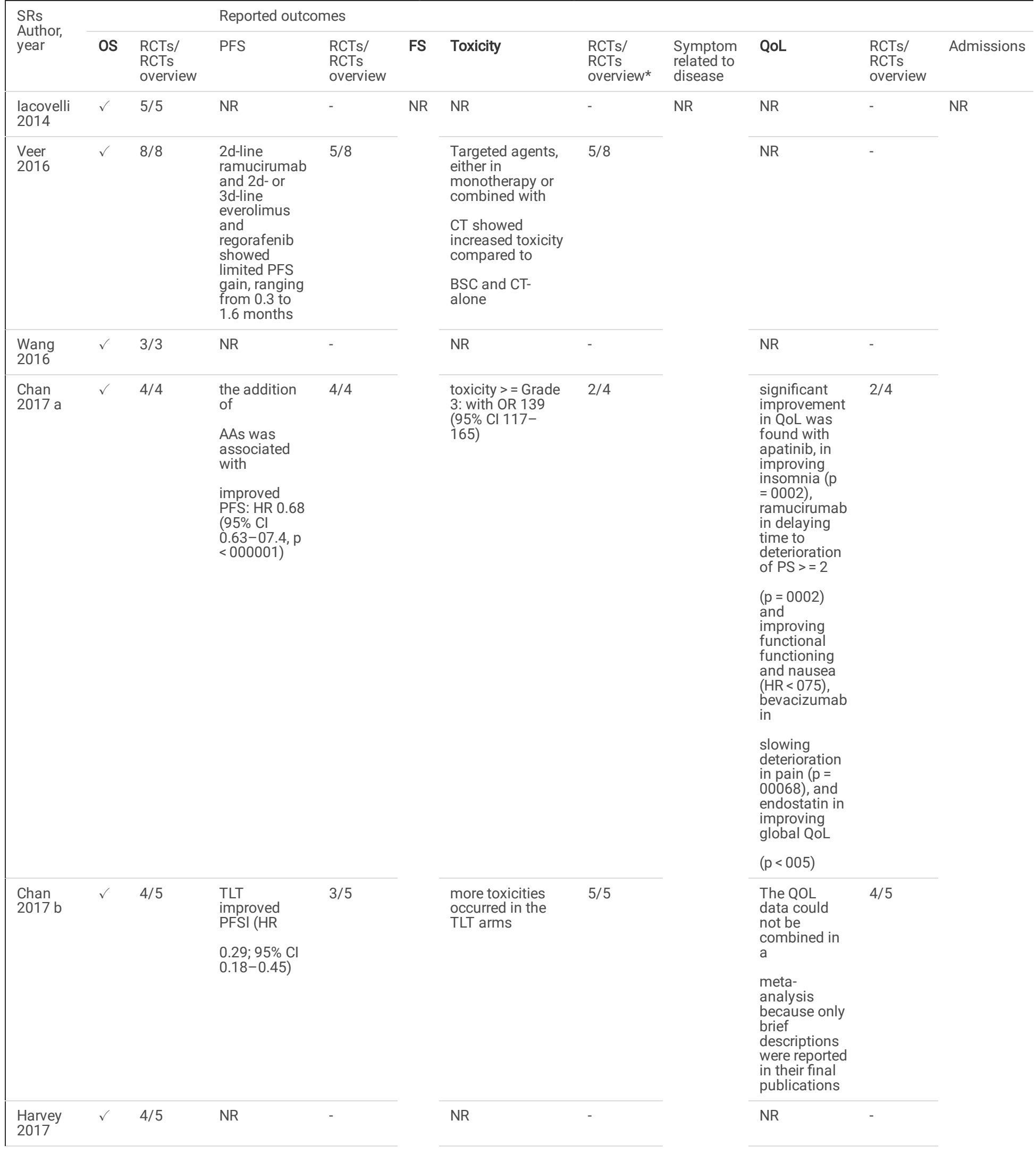

AAs: Anti-angiogenic agents; BSC: best supportive care; AE: Adverse events; CT: chemotherapy; FAE: Fatal adverse events; FS: Functional status; OS: Overall survival; PFS: Progression free survival;QoD: Quality of death; QoL: Quality of life; TA: Targeted agents; TLT: third line treatment.

Outcomes in bold are primary outcomes

OS has been presented in Fig. 4 (meta-analysis)

* RCTs: randomised controlled trials relevant to our question / RCTs overview: total randomized controlled trials included in the SR. 


\begin{tabular}{|c|c|c|c|c|c|c|c|c|}
\hline $\begin{array}{l}\text { Janmaat } \\
2017\end{array}$ & $\checkmark$ & $5 / 5$ & $\begin{array}{l}\text { people who } \\
\text { receive more } \\
\text { CT or } \\
\text { targeted } \\
\text { therapeutic } \\
\text { agents live } \\
\text { with } \\
\text { less disease } \\
\text { progression } \\
\text { than people } \\
\text { who receive } \\
\text { BSC or less } \\
\text { therapy }\end{array}$ & $2 / 5$ & NR & - & NR & - \\
\hline $\begin{array}{l}\text { Wagner } \\
2017\end{array}$ & $\checkmark$ & $3 / 3$ & NR & - & $\begin{array}{l}\text { Because of the } \\
\text { different ways of } \\
\text { reporting, grade I } \\
\text { to IV toxicities } \\
\text { can be compared } \\
\text { only within, } \\
\text { but not between } \\
\text { studies. Overall, } \\
\text { treatment- } \\
\text { associated } \\
\text { toxicities } \\
\text { were higher in the } \\
\text { combination of } \\
\text { CT arms, but this } \\
\text { was usually not } \\
\text { statistically } \\
\text { significant }\end{array}$ & $3 / 3$ & NR & - \\
\hline $\begin{array}{l}\text { Wang } \\
2017\end{array}$ & $\checkmark$ & $2 / 2$ & NR & $1 / 2$ & $\begin{array}{l}\text { the addition of } \\
\text { TAs to therapies } \\
\text { significantly } \\
\text { increased the risk } \\
\text { of developing } \\
\text { severe AEs (RR: } \\
1.12,95 \% \text { Cl: } \\
1.02-1.24, \mathrm{P}= \\
0.02 \text { ), but not for } \\
\text { FAEs (RR: } 0.97 \text {, } \\
95 \% \text { Cl: } 0.65- \\
1.45 \text {, } \\
\mathrm{P}=0.88 \text { ) }\end{array}$ & $2 / 2$ & NR & - \\
\hline Xie 2017 & NR & - & NR & - & $\begin{array}{l}\text { Compared with } \\
\text { other analyzed } \\
\text { treatments, } \\
\text { ramucirumab has } \\
\text { a higher risk of } \\
\text { hematological } \\
\text { events during its } \\
\text { application. } \\
\text { Lapatinib is } \\
\text { always combined } \\
\text { with severe } \\
\text { gastrointestinal } \\
\text { events. } \\
\text { Trastuzumab is } \\
\text { proposed for its } \\
\text { high efficacy in } \\
\text { improving the } \\
\text { survival rate and } \\
\text { safety, which is } \\
\text { proper for most } \\
\text { patients }\end{array}$ & $2 / 2$ & NR & - \\
\hline $\begin{array}{l}\text { Zhu } \\
2017\end{array}$ & $\checkmark$ & $5 / 5$ & NR & - & NR & - & NR & - \\
\hline
\end{tabular}

AAs: Anti-angiogenic agents; BSC: best supportive care; AE: Adverse events; CT: chemotherapy; FAE: Fatal adverse events; FS: Functional status; OS: Overall survival; PFS: Progression free survival;QoD: Quality of death; QoL: Quality of life; TA: Targeted agents; TLT: third line treatment.

Outcomes in bold are primary outcomes

OS has been presented in Fig. 4 (meta-analysis)

* RCTs: randomised controlled trials relevant to our question / RCTs overview: total randomized controlled trials included in the SR. 


\begin{tabular}{|c|c|c|c|c|c|c|c|c|}
\hline Liu 2018 & $\checkmark$ & $4 / 4$ & $\begin{array}{l}\text { PFS [HR } \\
0.50,95 \% \mathrm{Cl} \\
\\
\\
\\
(0.34,0.66), \\
\mathrm{P}<0.001]\end{array}$ & $4 / 4$ & $\begin{array}{l}\text { Fewer AESIs were } \\
\text { observed in the } \\
\text { VEGFR-Ab than } \\
\text { the VEGFR-TKI } \\
\text { drugs. VEGFR } \\
\text { drugs were } \\
\text { effective, and its } \\
\text { toxicity is within } \\
\text { a controllable } \\
\text { range }\end{array}$ & $4 / 4$ & NR & - \\
\hline $\begin{array}{l}\text { Zhao } \\
2018\end{array}$ & $\checkmark$ & $6 / 6$ & $\begin{array}{l}\text { apatinib } \\
(97.5 \%) \text { was } \\
\text { most likely to } \\
\text { improve PFS, } \\
\text { followed by } \\
\text { regorafenib } \\
(86.3 \%) \text { and } \\
\text { rilotumumab } \\
(65.4 \%) \text {. }\end{array}$ & $6 / 6$ & $\begin{array}{l}\text { bevacizumab } \\
(85.5 \%) \text { was } \\
\text { likely to get the } \\
\text { lowest severe } \\
\text { AEs, followed by } \\
\text { sunitinib }(63 \%)\end{array}$ & $5 / 6$ & NR & - \\
\hline $\begin{array}{l}\text { Chen } \\
2019\end{array}$ & $\checkmark$ & $2 / 2$ & NR & $1 / 2$ & $\begin{array}{l}\text { The most } \\
\text { common } \\
\text { grade } \geq 3 \text { TRAEs } \\
\text { were fatigue, } \\
\text { aspartate } \\
\text { aminotransferase } \\
\text { increased, } \\
\text { hepatitis, } \\
\text { pneumonitis, } \\
\text { colitis, } \\
\text { hypopituitarism. } \\
\text { The TRAE } \\
\text { incidence of anti- } \\
\text { PD- } 1 / \text { PD-L1 was } \\
\text { less than } \\
\text { chemotherapy } \\
\text { (TRAE RR }=0.64 \\
\text { p }<0.001 ; \geq 3 \\
\text { TRAE RR }=0.37 \mathrm{p} \\
<0.001) \text {. The } \\
\text { incidence of } \geq 3 \\
\text { TRAEs of anti- } \\
\text { PD-1/PD-L1 } 1 \\
\text { treatment was } \\
\text { less than that of } \\
\text { anti-CTLA-4 } \\
\text { (11.7\% vs } 43.9 \% \text { ) }\end{array}$ & $2 / 2$ & NR & - \\
\hline $\begin{array}{l}\text { vanKleef } \\
2019\end{array}$ & NR & - & NR & - & NR & - & $\begin{array}{l}\text { taxanes and } \\
\text { targeted } \\
\text { agents could } \\
\text { provide } \\
\text { HRQoL } \\
\text { benefit } \\
\text { beyond first } \\
\text { line } \\
\text { compared } \\
\text { with BSC }\end{array}$ & $8 / 8$ \\
\hline
\end{tabular}

AAs: Anti-angiogenic agents; BSC: best supportive care; AE: Adverse events; CT: chemotherapy; FAE: Fatal adverse events; FS: Functional status; OS: Overall survival; PFS: Progression free survival;QoD: Quality of death; QoL: Quality of life; TA: Targeted agents; TLT: third line treatment.

Outcomes in bold are primary outcomes

OS has been presented in Fig. 4 (meta-analysis)

* RCTs: randomised controlled trials relevant to our question / RCTs overview: total randomized controlled trials included in the SR. 
AAs: Anti-angiogenic agents; BSC: best supportive care; AE: Adverse events; CT: chemotherapy; FAE: Fatal adverse events; FS: Functional status; OS: Overall survival; PFS: Progression free survival;QoD: Quality of death; QoL: Quality of life; TA: Targeted agents; TLT: third line treatment.

Outcomes in bold are primary outcomes

OS has been presented in Fig. 4 (meta-analysis)

* RCTs: randomised controlled trials relevant to our question / RCTs overview: total randomized controlled trials included in the SR.

\section{Discussion}

This overview provided a comprehensive synthesis of the available evidence regarding the effectiveness of SOT compared with BSC or placebo administered in patients with advanced esophageal or gastric cancers. The current analyses revealed that it is uncertain whether SOT, such as CT, immunotherapy, biological and targeted therapy improve OS and PFS over more conservative approaches due to the very low certainty of evidence. Most reviews had a critically low methodological quality and did not include outcomes considered important in decision-making.

\section{Context}

Over the last two decades, cancer care's aggressiveness near the EOL has emerged as a growing concern.(38, 39) For instance, the American Society of Clinical Oncology (ASCO) recommends avoiding the use of CT near the EOL due to the absence of evidence supporting its clinical value. (40) This is in the line with our results, confirming the limited attention that patient-centered outcomes have received so far. Usually SRs only meta-analyze clinical outcomes such as OS or PFS but do not include others like FS, toxicity, or symptoms related to the disease, admissions to the hospital, or palliative care provided during the last year. All of these outcomes are particularly relevant for patients with a high risk of dying in the short or medium-term. These evidence gaps in reporting essential outcomes for patients could reflect either lack of primary data availability in the respective studies or event or lack of interest by authors of SRs to analyze this data actively.

Treatment for locally advanced, unresectable esophageal or gastric cancers remains highly controversial. For example, the European Society of Medical Oncology (ESMO) guidelines are not well-defined in this regard. (41) They recommend systemic treatment (CT) for patients with inoperable locally advanced and/or metastatic (stage IV) disease, based on improved survival and QoL compared to BSC alone (I, A). However, comorbidities, organ function, and PS must always be taken into consideration. (II, B). This recommendation is based on small randomised trials or large randomised trials with a suspicion of bias (lower methodological quality) or meta-analyses of such trials or of trials with demonstrated heterogeneity. As we have stated, our overview's results do not go in the same direction as those guidelines recommendations due to the low quality of the evidence to support an active systemic treatment in patients with advanced stages with a high risk of dying in the short or medium-term. It is important to note that all the mentioned guidelines recommendations for all the different SOT regimens are mainly based on a potential OS improvement of a few months and rarely consider patient-centered outcomes.

Although there is evidence suggesting that SOT's use near the EOL is not related to its likelihood of providing benefit (27, 42-44), our analysis could not confirm any significant differences between SOT and BSC for all the outcomes. The discussion about changing the focus of treatment to providing symptomatic and supportive care is complex. Little literature addresses the magnitude of financial, psychological, or physical harms of medication overuse in cancer, even when it could be substantial.(45) Smith and Hillner have proposed for patients with advanced cancer, changes in medical oncologists' behavior, and changes in their attitudes and practices that will bend the cancer-cost curve.(46) For patients with advanced esophageal and gastric cancers, we can consider the following aspects: a) to limit second-line and third-line treatment for metastatic cancer to sequential monotherapies; b) to limit CT to patients with good PS; c) to limit further CT to clinical trials in the case of patients who are not responding to three consecutive regimens. Besides, regarding changes in attitudes and practice, we agree with the author that better integration of palliative care into usual oncology care must be discussed.

One problem to solve is how supportive care and BSC are implemented in RCTs when used as a comparison treatment arm. Reviews of the cancer clinical trial literature found that RCTs poorly define and standardize BSC as a clinical trial control arm. $(47,48)$ Such studies risk systematically over-estimating the net clinical effect of the comparator arms. The vast majority of the studies did not meet the WHO guidelines on BSC because palliative care therapies were not recommended or integrated into care.

Another issue is how studies entitle the patients reported outcomes (PROs). The heterogeneity in the constructs, measures, and analytic is very challenging to interpret.(49) As we found in our study, especially in adverse events, it is important to take responsibility for the need to strengthen the rigor of PROs in cancer trials or studies reports. It is also essential to acknowledge the discordances between patient and clinician reports regard the symptoms and severity. (50, 51 ) It could be useful to follow the Patient-Reported Outcome Terminology Criteria for Adverse Events (PRO-CTAE) tools in a case to be necessary and finally to consider all the submitted PROs as important supportive data improving the validity, reliability, and precision of adverse events report.

\section{Limitations}

We are aware that our research may have limitations. Firstly, the main limitation of this overview arises from heterogeneity amongst active treatments assessed. In this regard, we assessed the included studies' heterogeneity and undertook analysis by type of SOT.

Secondly, we found that the overlapping RCT distribution may over-represent samples from these primary studies. Nevertheless, we reported this overlap and quantified it using the mentioned CCA method to help us consider questions that could affect our overview's comprehensiveness and complexity. 
Finally, the risk of bias assessment of primary studies was not performed directly on the original studies but each SR, resulting in an incomplete assessment for some studies and potentially hindering the overall assessment. We plan to carry out an evidence map and a new SR to address these limitations.

\section{Implications}

This overview did not identify solid evidence for administering SOT over BSC for patients with advanced esophageal or gastric cancers. Involved doctors and patients should be aware of the limited benefits that intensive SOT can provide when the disease is very advanced. The therapeutic decisions for patients with advanced esophageal or gastric cancers must consider their FS, values and preferences, and potential side effects of treatments. However, to enable patients to make informed choices, they should be provided with balanced information. Unfortunately, as shown in our overview, clinical trials and SRs barely report patient-centered outcomes.

It is important to note that almost all RCTs for patients with esophageal or gastric cancers currently focus on treating the disease's early stages. However, the evidence collected in this overview shows that it is still necessary to evaluate how to treat patients in advanced stages. We claim future clinical trials and reviews to address SOT's impact in patients with advanced stages at high risk of dying in the short or medium-term. We do so by considering that before comparing intensive treatments, these should demonstrate their advantages over more conservative approaches such as BSC, not only on survival but also on patient-centered outcomes. High-quality SRs with complete reporting of design, methodology, and analysis of results could perform pre-planned subgroup analyses to identify those groups of patients more prone to benefit from intensive systemic treatments and avoid the accompanying side effects.

\section{Conclusions}

This overview suggests that there is a large uncertainty on the effectiveness of SOT for advanced esophageal or gastric cancers that could provide a complete understanding of benefits and side effects. Broader research, including high-quality SRs and further RCTs that consider a thorough assessment of patientcentered outcomes, is needed to identify improvement targets to optimize cancer care value.

\section{Abbreviations}

\section{AMSTAR}

A MeaSurement Tool to Assess systematic Reviews; ASCO:American Society of Clinical Oncology; BSC:Best supportive care; CCA:Corrected covered area; $\mathrm{Cl}$ :Confidence interval; CT:chemotherapy; EMBASE:Excerpta Medica dataBASE; EOL:end-of-life; ESMO:European Society for Medical Oncology; FS:functional status; GEJ:gastro-esophagic junction; GRADE:Grading of Recommendations Assessment, Development, and Evaluation; HR:hazard ratio; MEDLINE:Medical Literature Analysis and Retrieval System Online; OR:Odds ratio; OS:Overall survival; PFS:Progression free survival; PRISMA:Preferred Reporting Items for Systematic reviews and Meta-Analyses; PROSPERO:International Prospective Register of Systematic Reviews; PROs:patients reported outcomes; PROCTAE:Patient-Reported Outcome Terminology Criteria for Adverse Events; QoL:Quality of life; RCTs:Randomised controlled trials; SoF:Summary of finding; SRs:systematic reviews; SOT:systemic oncological treatment; VEGFR:vascular endothelial growth factor receptor; WHO:World Health Organization.

\section{Declarations}

\section{Ethics approval and consent to participate}

Not applicable

\section{Consent for publication}

Not applicable

\section{Availability of data and materials}

The protocol of the current study is available in the OSF repository, https://osf.io/7chx6/ Accessed 11 January 2021 (DOI 10.17605/OSF.IO/7CHX6). Search strategies needed to replicate the study are included in the supplement materials file.

\section{Competing interests}

The authors declare that they have no competing interests

\section{Funding}

This study is funded through a grant from Instituto de Salud Carlos III (PI18/00034) co-financed by funds from the European Regional Development Fund.

\section{Acknowledgments}

Marilina Santero is a doctoral candidate for the PhD in Methodology of Biomedical Research and Public Health (Department of Paediatrics, Obstetrics, Gynaecology and Preventive Medicine), Universidad Autònoma de Barcelona, Barcelona, Spain.

\section{Authors' contributions}


MS, JPB, IS and XBC conceived and designed the overview. KSG, AMA, CR, JS, ARA, GRG, RAD, AGM, JPB, and MS participated in the study selection and data extraction. MS, RAD, AGM, and JPB contributed to the interpretation of the findings. MS, AGM, and RAD wrote the drafts and prepared the manuscript. JPB,

$M J Q$, and XBC provided supervisory support and reviewed this paper. All authors contributed to their vision of the manuscript and approved the final version of the review.

\section{Authors' information}

(1) Iberoamerican Cochrane Centre, Biomedical Research Institute Sant Pau (IIB Sant Pau), Barcelona, Spain. (2) Interdisciplinary Centre for Health Studies (CIESAL), Universidad de Valparaíso, Viña del Mar, Chile. (3) Department of Physical Therapy, Faculty of Medicine, Universidad de Chile, Santiago, Chile. (4) CIBER Epidemiología y Salud Pública (CIBERESP), Barcelona, Spain.

\section{References}

1. Bray F, Ferlay J, Soerjomataram I, Siegel RL, Torre LA, Jemal A. Global cancer statistics 2018: GLOBOCAN estimates of incidence and mortality worldwide for 36 cancers in 185 countries. CA: a cancer journal for clinicians. 2018;68(6):394-424.

2. The Institute for Health Metrics and Evaluation (IHME). IHME Data. GBD Results Tool 2020 [Available from: http://ghdx.healthdata.org/gbd-results-tool.

3. Zhang Y. Epidemiology of esophageal cancer. World Journal of Gastroenterology: WJG. 2013;19(34):5598.

4. Crew KD, Neugut Al. Epidemiology of gastric cancer. World journal of gastroenterology: WJG. 2006;12(3):354.

5. Howlader N, Noone A, Krapcho M. SEER Cancer Statistics Review, 1975-2014, based on November 2016 SEER data submission. Bethesda, MD: National Cancer Institute. 2017.

6. Hui D, Nooruddin Z, Didwaniya N, Dev R, De La Cruz M, Kim SH, et al. Concepts and definitions for "actively dying",区"end of life", "terminally ill", "terminal care", "transition of care": a systematic review. Journal of pain and symptom management. 2014;47(1):77-89.

7. Lunney J. Redefining our definition of end of life. J Hosp Palliat Nurs. 2001;3:5-6.

8. Wagner AD, Grothe W, Haerting J, Kleber G, Grothey A, Fleig WE. Chemotherapy in advanced gastric cancer: a systematic review and meta-analysis based on aggregate data. J Clin Oncol. 2006;24(18):2903-9.

9. Epistola RJ, Chao J. Systemic therapy for advanced gastroesophageal cancers: progress and pitfalls. Translational Gastroenterology and Hepatology. 2020;5.

10. Blazeby JM, Farndon JR, Donovan J, Alderson D. A prospective longitudinal study examining the quality of life of patients with esophageal carcinoma. Cancer: Interdisciplinary International Journal of the American Cancer Society. 2000;88(8):1781-7.

11. Keam B, Oh D-Y, Lee S-H, Kim D-W, Kim MR, Im S-A, et al. Aggressiveness of Cancer-Care near the End-of-Life in Korea. Japanese Journal of Clinical Oncology. 2008;38(5):381-6.

12. Bergman J, Laviana AA. Opportunities to maximize value with integrated palliative care. Journal of Multidisciplinary Healthcare. 2016;9:219.

13. Dalhammar K, Malmstrom M, Schelin M, Falkenback D, Kristensson J. The impact of initial treatment strategy and survival time on quality of end-of-life care among patients with oesophageal and gastric cancer: A population-based cohort study. PLOS one. 2020;15(6):e0235045.

14. Cunningham SC, Schulick RD. Palliative management of gastric cancer. Surgical oncology. 2007;16(4):267-75.

15. Janmaat VT, Steyerberg EW, van der Gaast A, Mathijssen RH, Bruno MJ, Peppelenbosch MP, et al. Palliative chemotherapy and targeted therapies for esophageal and gastroesophageal junction cancer. Cochrane Database of Systematic Reviews. 2017(11).

16. Pérez-Bracchiglione J RC, Solà I, Acosta-Dighero R, Santero M, Salas-Gama K, et al. . Efficacy of systemic oncological treatments in patients with advanced, non-intestinal digestive cancer at high risk of dying in the middle and short term: evidence synthesis 2020.

17. Higgins JP, Thomas J, Chandler J, Cumpston M, Li T, Page MJ, et al. Cochrane handbook for systematic reviews of interventions: John Wiley \& Sons; 2019.

18. Stewart LA, Clarke M, Rovers M, Riley RD, Simmonds M, Stewart G, et al. Preferred reporting items for a systematic review and meta-analysis of individual participant data: the PRISMA-IPD statement. JAMA. 2015;313(16):1657-65.

19. Veritas Health Innovation. Covidence systematic review software. Veritas Health Innovation Melbourne, Australia; 2016.

20. Shea BJ, Reeves BC, Wells G, Thuku M, Hamel C, Moran J, et al. AMSTAR 2: a critical appraisal tool for systematic reviews that include randomised or non-randomised studies of healthcare interventions, or both. bmj. 2017;358:j4008.

21. Pieper D, Antoine S-L, Mathes T, Neugebauer EA, Eikermann M. Systematic review finds overlapping reviews were not mentioned in every other overview. Journal of clinical epidemiology. 2014;67(4):368-75.

22. Guyatt GH, Oxman AD, Vist GE, Kunz R, Falck-Ytter Y, Alonso-Coello $P$, et al. GRADE: an emerging consensus on rating quality of evidence and strength of recommendations. bmj. 2008;336(7650):924-6.

23. lacovelli R, Pietrantonio F, Farcomeni A, Maggi C, Palazzo A, Ricchini F, et al. Chemotherapy or targeted therapy as second-line treatment of advanced gastric cancer. A systematic review and meta-analysis of published studies. Plos one. 2014;9(9):e108940.

24. Ter Veer E, Mohammad NH, van Valkenhoef G, Ngai LL, Mali RM, van Oijen MG, et al. Second-and third-line systemic therapy in patients with advanced esophagogastric cancer: a systematic review of the literature. Cancer and Metastasis Reviews. 2016;35(3):439-56.

25. Wang C, Fang X. The role of targeted agents in the treatment of advanced gastric cancer: a meta-analysis of randomized controlled trials. Eur Rev Med Pharmacol Sci. 2016;20(9):1725-32. 
26. Chan DL, Sjoquist KM, Goldstein D, Price TJ, Martin AJ, Bang Y-J, et al. The effect of anti-angiogenic agents on overall survival in metastatic oesophagogastric cancer: A systematic review and meta-analysis. PLOS one. 2017;12(2):e0172307.

27. Chan W-I, Yuen K-k, Siu SW-k, Lam K-o, Kwong DL-W. Third-line systemic treatment versus best supportive care for advanced/metastatic gastric cancer: a systematic review and meta-analysis. Critical Reviews in Oncology/Hematology. 2017;116:68-81.

28. Harvey RC. Second-line treatments for advanced gastric cancer: A network meta-analysis of overall survival using parametric modelling methods. Oncology and therapy. 2017;5(1):53-67.

29. Wagner AD, Syn NL, Moehler M, Grothe W, Yong WP, Tai BC, et al. Chemotherapy for advanced gastric cancer. Cochrane Database of Systematic Reviews. 2017(8).

30. Wang L, Liu Y, Zhou W, Li W. Treatment-related severe and fatal adverse events with molecular targeted agents in the treatment of advanced gastric cancer: a meta-analysis. OncoTargets and therapy. 2017;10:2281.

31. Xie S, Zhang H, Wang X, Ge Q, Hu J. The relative efficacy and safety of targeted agents used in combination with chemotherapy in treating patients with untreated advanced gastric cancer: a network meta-analysis. Oncotarget. 2017;8(16):26959.

32. Zhu X, Ko Y-J, Berry S, Shah K, Lee E, Chan K. A Bayesian network meta-analysis on second-line systemic therapy in advanced gastric cancer. Gastric Cancer. 2017;20(4):646-54.

33. Liu D, Ma X, Xiao D, Jia Y, Wang Y. Efficacy and safety of targeting VEGFR drugs in treatment for advanced or metastatic gastric cancer: a systemic review and meta-analysis. Oncotarget. 2018;9(8):8120.

34. Zhao T-T, Xu H, Xu H-M, Wang Z-N, Xu Y-Y, Song Y-X, et al. The efficacy and safety of targeted therapy with or without chemotherapy in advanced gastric cancer treatment: a network meta-analysis of well-designed randomized controlled trials. Gastric Cancer. 2018;21(3):361-71.

35. Chen C, Zhang F, Zhou N, Gu Y-M, Zhang Y-T, He Y-D, et al. Efficacy and safety of immune checkpoint inhibitors in advanced gastric or gastroesophageal junction cancer: a systematic review and meta-analysis. Oncoimmunology. 2019;8(5):e1581547.

36. van Kleef JJ, Ter Veer E, van den Boorn HcG, Schokker S, Ngai LL, Prins MJ, et al. Quality of life during palliative systemic therapy for esophagogastric cancer: systematic review and meta-analysis. JNCl: Journal of the National Cancer Institute. 2020;112(1):12-29.

37. Wallis CJ, Butaney M, Satkunasivam R, Freedland SJ, Patel SP, Hamid O, et al. Association of patient sex with efficacy of immune checkpoint inhibitors and overall survival in advanced cancers: a systematic review and meta-analysis. JAMA oncology. 2019;5(4):529-36.

38. Earle CC, Landrum MB, Souza JM, Neville BA, Weeks JC, Ayanian JZ. Aggressiveness of cancer care near the end of life: is it a quality-of-care issue? Journal of clinical oncology. 2008;26(23):3860.

39. Martoni AA, Tanneberger S, Mutri V. Cancer chemotherapy near the end of life: the time has come to set guidelines for its appropriate use. Tumori Journal. 2007;93(5):417-22.

40. Schnipper LE, Smith TJ, Raghavan D, Blayney DW, Ganz PA, Mulvey TM, et al. American Society of Clinical Oncology identifies five key opportunities to improve care and reduce costs: the top five list for oncology. J Clin Oncol. 2012;30(14):1715-24.

41. Smyth E, Verheij M, Allum W, Cunningham D, Cervantes A, Arnold D. Gastric cancer: ESMO Clinical Practice Guidelines for diagnosis, treatment and followup. Annals of oncology. 2016;27(suppl_5):v38-v49.

42. Zhang Z, Gu X-L, Chen M-L, Liu M-H, Zhao W-W, Cheng W-W. Use of palliative chemo-and radiotherapy at the end of life in patients with cancer: a retrospective cohort study. American Journal of Hospice and Palliative Medicine. 2017;34(9):801-5.

43. Sheng J, Zhang YX, He XB, Fang WF, Yang YP, Lin GN, et al. Chemotherapy near the end of life for Chinese patients with solid malignancies. The oncologist. 2017;22(1):53.

44. Hong JH, Rho S-Y, Hong YS. Trends in the aggressiveness of end-of-life care for advanced stomach cancer patients. Cancer research and treatment: official journal of Korean Cancer Association. 2013;45(4):270.

45. Schleicher SM, Bach PB, Matsoukas K, Korenstein D. Medication overuse in oncology: current trends and future implications for patients and society. The Lancet Oncology. 2018;19(4):e200-e8.

46. Smith TJ, Hillner BE. Bending the cost curve in cancer care. The New England journal of medicine. 2011;364(21):2060.

47. Nipp R, Currow D, Cherny N, Strasser F, Abernethy A, Zafar S. Best supportive care in clinical trials: review of the inconsistency in control arm design. British journal of cancer. 2015;113(1):6-11.

48. Lee RT, Ramchandran K, Sanft T, Von Roenn J. Implementation of supportive care and best supportive care interventions in clinical trials enrolling patients with cancer. Annals of oncology. 2015;26(9):1838-45.

49. Kluetz PG, Chingos DT, Basch EM, Mitchell SA. Patient-reported outcomes in cancer clinical trials: measuring symptomatic adverse events with the National Cancer Institute Patient-Reported Outcomes Version of the Common Terminology Criteria for Adverse Events (PRO-CTCAE). American Society of Clinical Oncology Educational Book. 2016;36:67-73.

50. Basch E, lasonos A, McDonough T, Barz A, Culkin A, Kris MG, et al. Patient versus clinician symptom reporting using the National Cancer Institute Common Terminology Criteria for Adverse Events: results of a questionnaire-based study. The Lancet Oncology. 2006;7(11):903-9.

51. Xiao C, Polomano R, Bruner DW. Comparison between patient-reported and clinician-observed symptoms in oncology. Cancer Nursing. 2013;36(6):E1-E16.

\section{Additional Files}

Appendix 1. Protocol study (PDF); 
Appendix 2: Complete PRISMA checklist. The PRISMA checklist was completed in full with page number of the paper which reports the information that meets the criteria of the checklist (PDF);

Appendix 3: Search strategy (PDF);

Appendix 4: List of excluded reviews and justification for the exclusions (PDF);

Appendix 5: Further characteristics of included systematic reviews (PDF);

Appendix 6: References RCTs (PDF);

Appendix 7: GRADE (PDF)

\section{Figures}

Eligibility criteria PICOT framework
Patients
Adults > 18 years of age.
Esophageal or gastric cancer, primary or recurrent, in
stage III or IV (advanced) or metastatic (excluded
lymphatic, stromal, and neuroendocrine cancers).
Interventions
Any chemotherapy (CT), either monotherapy or in
combination, or another oncological treatment (biological,
targeted therapy or immunotherapy), whether individual or
combined, with or without supportive care.
Comparators
Any supportive treatment, usual treatment, or BSC.
Placebo.
Outcomes
Functionical outcomes: Survival, Progression-free survival,
Patient-centered outcomes: Symptoms related to the
disease; Quality of life; Admissions to hospital or long-term
center, or emergency consultations; Quality of death
(Admission to the hospital at the end-of-life; Palliative care
provided during the last year; Place of death)
Timing
Studies published from 2008 onwards.
Systemic and study design
cancers at high risk of dying in the short or medium-term
Systematic reviews that assessed the impact of

\section{Figure 1}

Eligibility criteria 


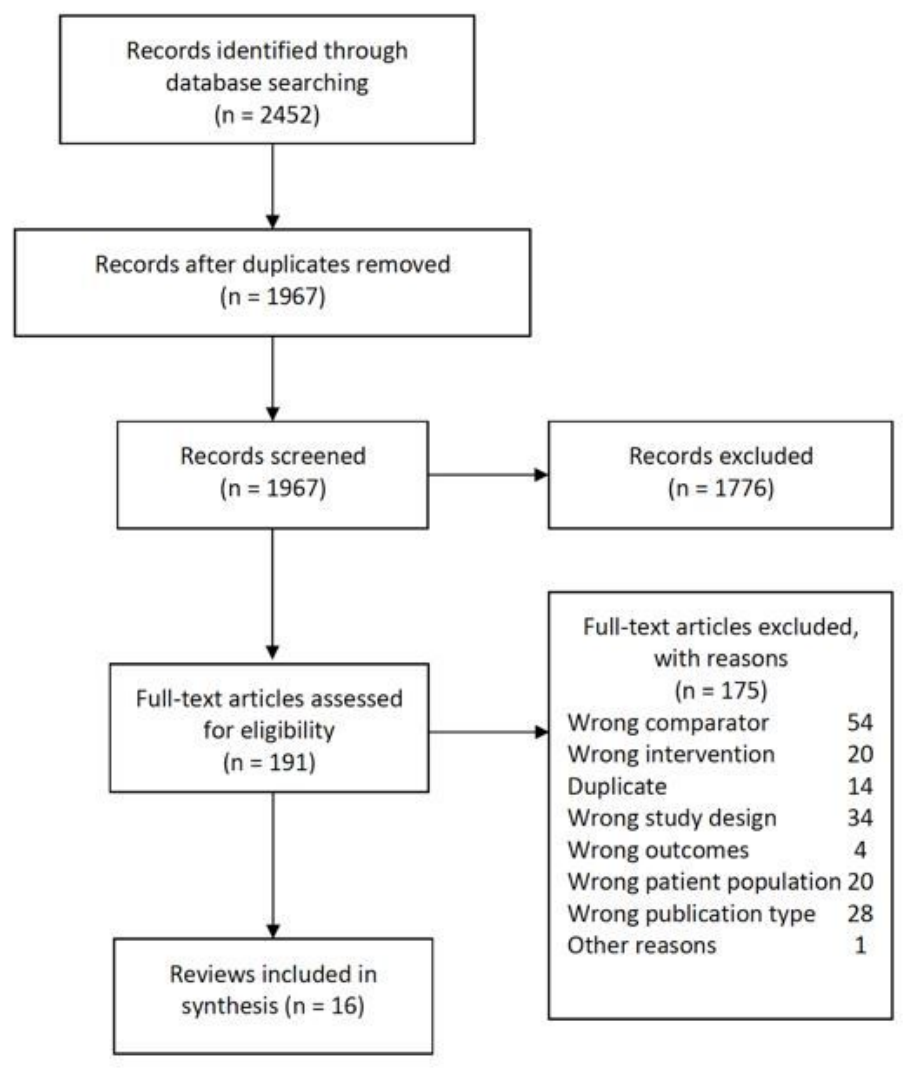

Figure 2

PRISMA flow diagram 


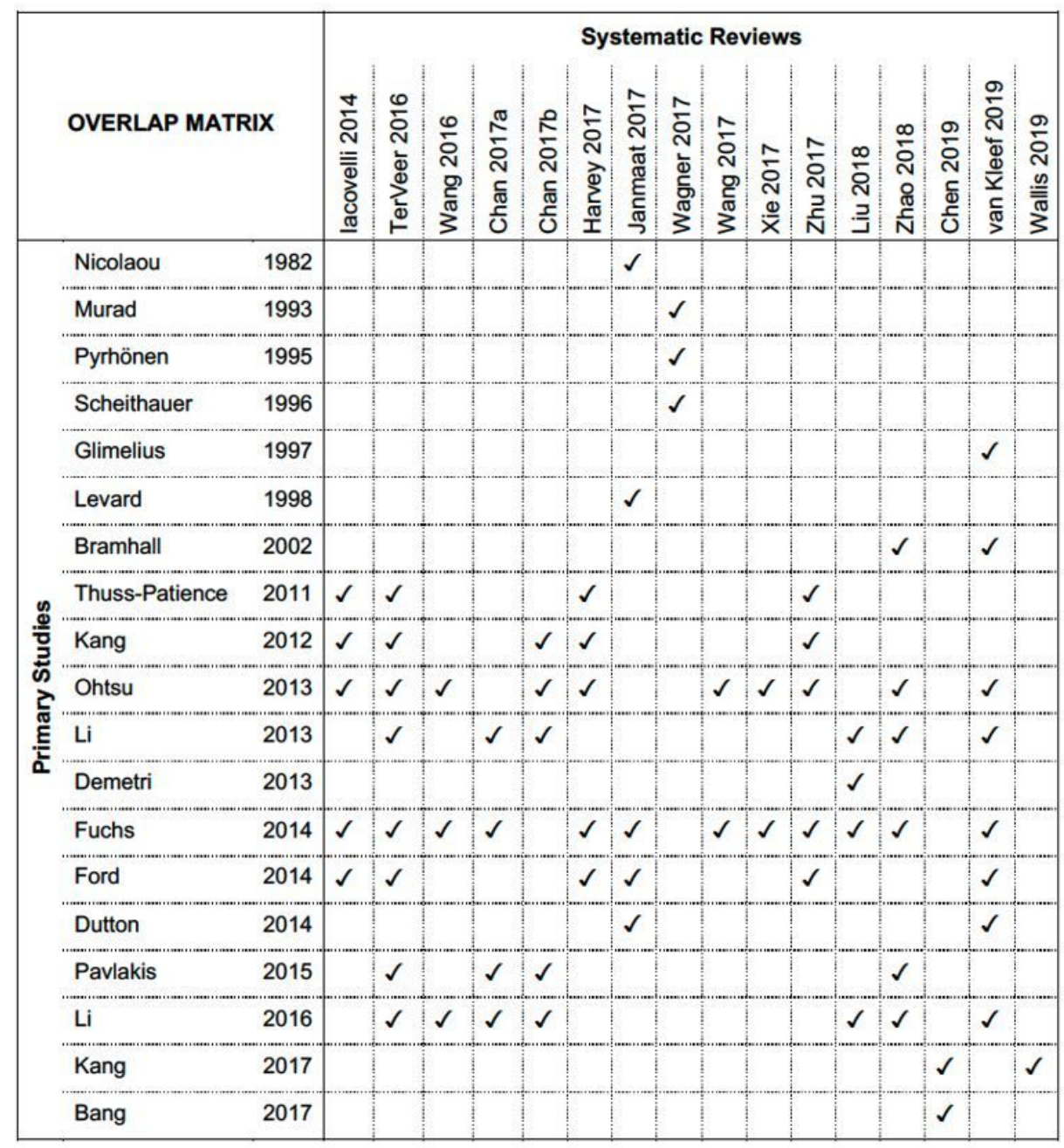

\section{Figure 3}

Overlap matrix 


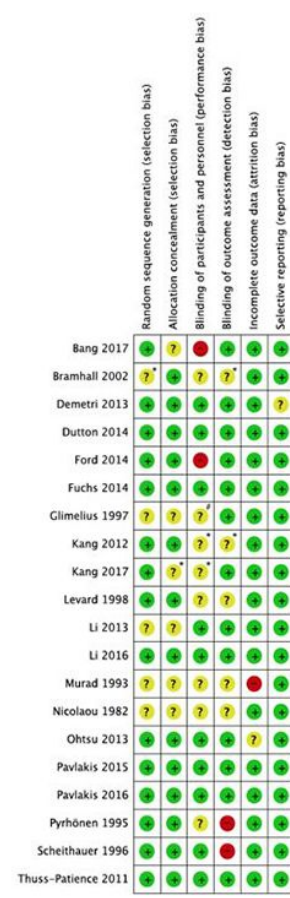

A

B

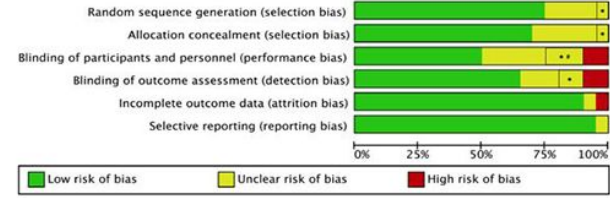

Risk of bias graph. Consensus of the systematic reviews on each element of risk of bias (A) for each included study and (B) as a percentage of risk present in each element.

Figure 4

Risk of bias Assessment 
1

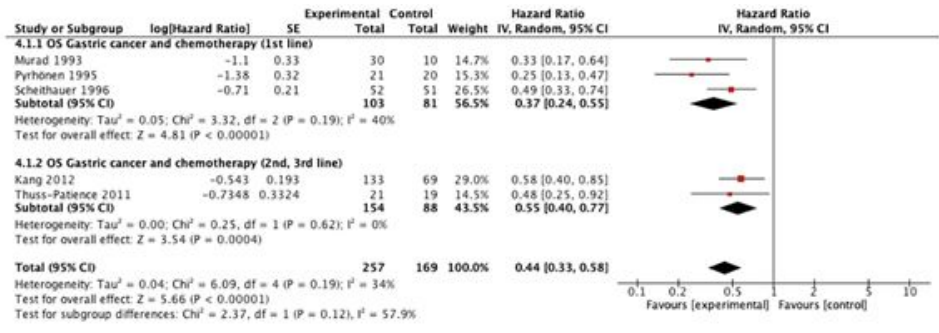

2

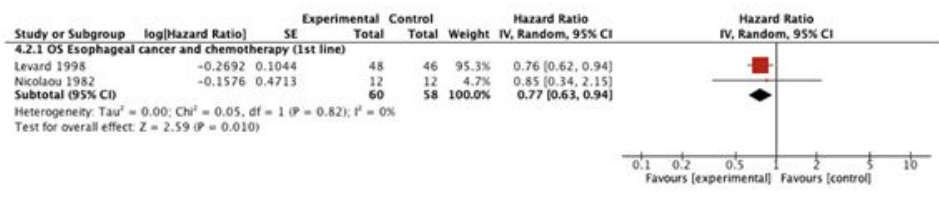

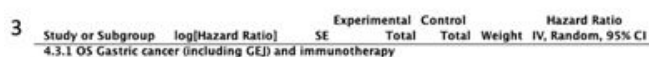

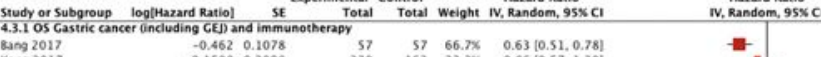

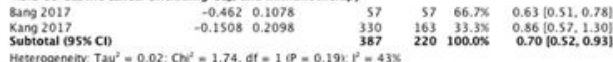

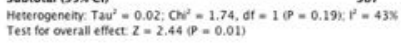

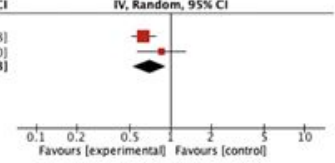

4

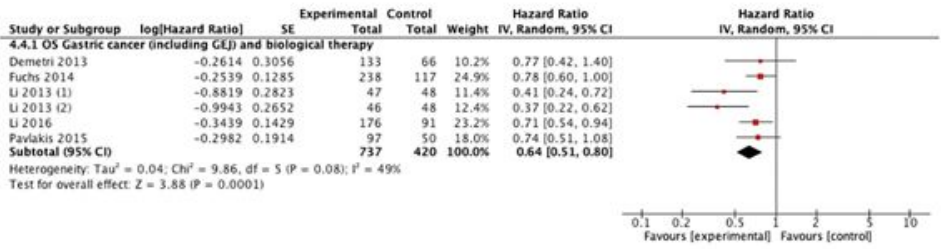

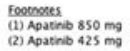

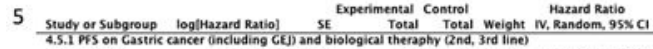

Dementrin 2013
fuchs 2014

42013 i.

$42013(2)$
42016

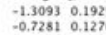

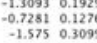

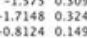

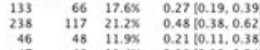

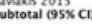

$-0.90030 .1901$

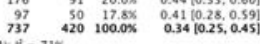

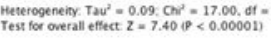
$37=71 x^{40}$

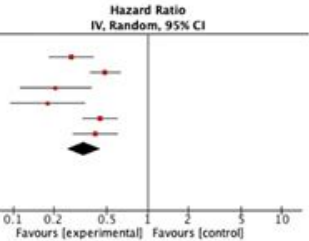

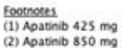

Figure 5

Overall survival and progression-free survival for systemic oncological treatment versus supportive treatment in advanced esophageal or gastric cancers

\section{Supplementary Files}

This is a list of supplementary files associated with this preprint. Click to download.

- Appendix1.pdf

- Appendix2.pdf

- Appendix3.pdf

- Appendix4.pdf

- Appendix5.pdf

- Appendix6.pdf

- Appendix7.pdf 